\title{
A BERNSTEIN TYPE INEQUALITY FOR NOD RANDOM VARIABLES AND APPLICATIONS
}

\author{
Pingyan Chen And Soo HaK Sung
}

\begin{abstract}
The Bernstein inequality is an exponential probability inequality for a sequence of bounded independent random variables. In this paper, we prove a Bernstein type inequality for unbounded negatively orthant dependent (NOD) random variables. As some applications, we obtain the convergence rates of the law of the iterated logarithm and law of the single logarithm for identically distributed NOD random variables. We also obtain a strong law for weighted sums of NOD random variables.
\end{abstract}

Mathematics subject classification (2010): 60F15.

Keywords and phrases: Bernstein inequality, exponential inequality, convergence rate, weighted sum, negatively orthant dependent random variables.

\section{REFERENCES}

[1] K. Alam, K. M. L. Saxena, Positive dependence in multivariate distributions, Commun. Statist. Theor. Meth. 10 (1981), 1183-1196.

[2] P. Chen, X. MA, S. H. Sung, On complete convergence and strong law for weighted sums of i.i.d. random variables, Abst. Appl. Anal. 2014 (2014), Article ID 251435, 1-7.

[3] T. C. Christofides, M. HAdjikyriakou, Exponential inequalities for $N$-demimartingales and negatively associated random variables, Statist. Probab. Lett. 79 (2009), 2060-2065.

[4] J. A. DAVIS, Convergence rates for the law of the iterated logarithm, Ann. Math. Statist. 39 (1968), $1479-1485$.

[5] U. Einmahl, D. LI, Characterization of LIL behavior in Banach space, Trans. Amer. Math. Soc. 360 (2008), 6677-6693.

[6] A. GuT, Convergence rates for probabilities of moderate deviations for sums of random variables with multidimensional indices, Ann. Probab. 8 (1980), 298-313.

[7] H. JABBARI, M. JABBARI, H. A. AZARNOOSH, An exponential inequality for negatively associated random variables, Electron. J. Stat. 3 (2009), 165-175.

[8] B. Y. JING, H. Y. LiAnG, Strong limit theorems for weighted sums of negatively associated random variables, J. Theor. Probab. 21 (2008), 890-909.

[9] K. JoAg-Dev, F. Proschan, Negative association of random variables with applications, Ann. Statist. 11 (1983), 286-295.

[10] T. S. Kiм, H. C. KIM, On the exponential inequality for negative dependent sequence, Commun. Korean Math. Soc. 22 (2007), 315-321.

[11] T. L. LAI, Limit theorems for delayed sums, Ann. Probab. 2 (1974), 432-440.

[12] E. L. Lehmann, Some concepts of dependence, Ann. Math. Statist. 37 (1966), 1137-1153.

[13] D. LI, M. B. RAO, T. JIANG, X. WANG, Complete convergence and almost sure convergence of weighted sums of random variables, J. Theor. Probab. 8 (1995), 49-76.

[14] H. J. Nooghabi, H. A. Azarnoosh, Exponential inequality for negatively associated random variables, Stat. Papers 50 (2009), 419-428.

[15] G. G. Rouss As, Exponential probability inequalities with some applications, IMS Lecture Notes Monograph Series, vol. 30 (1996), 303-319.

[16] Q. M. SHAO, A comparison theorem on moment inequalities between negatively associated and independent random variables, J. Theoret. Probab. 13 (2000), 343-356. 
[17] W. F. Stout, Almost Sure Convergence, Academic Press, New York (1974).

[18] S. H. SunG, An exponential inequality for negatively associated random variables, J. Ineq. Appl. 2009 (2009), Article ID 649427, 1-7.

[19] S. H. Sung, On the exponential inequalities for negatively dependent random variables, J. Math. Anal. Appl. 381 (2011), 538-545.

[20] R. L. TAYlor, R. F. Patterson, A. Bozorgnia, A strong law of large numbers for arrays of rowwise negatively dependent random variables, Stoch. Anal. Appl. 20 (2002), 643-656.

[21] X. WANG, S. Hu, A. SHEN, W. YANG, An exponential inequality for a NOD sequence and a strong law of large numbers, Appl. Math. Lett. 24 (2011), 219-223.

[22] G. XING, On the exponential inequalities for strictly stationary and negatively associated random variables, J. Statist. Plan. Infer. 139 (2009), 3453-3460.

[23] G. XING, S. YANG, An exponential inequality for strictly stationary and negatively associated random variables, Commun. Ststist. Theor. Meth. 39 (2010), 340-349.

[24] G. XING, S. YANG, A. LIU, X. WANG, A remark on the exponential inequality for negatively associated random variables, J. Korean Statist. Soc. 38 (2009), 53-57.

[25] S. YANG, Uniformly asymptotic normality of the regression weighted estimator for negatively associated samples, Statist. Probab. Lett. 62 (2003), 101-110.

[26] X. ZHOU, Complete moment convergence of moving average processes under $\varphi$-mixing assumptions, Statist. Probab. Lett. 80 (2010), 285-292. 